\title{
MFN status and the choice of tariff regime
}

Article

Accepted Version

Hashimzade, N., Khodavaisi, H. and Myles, G. D. (2011) MFN status and the choice of tariff regime. Open Economies Review, 22 (5). pp. 847-874. ISSN 1573-708X doi: https://doi.org/10.1007/s11079-010-9178-9 Available at https://centaur.reading.ac.uk/8035/

It is advisable to refer to the publisher's version if you intend to cite from the work. See Guidance on citing.

To link to this article DOI: http://dx.doi.org/10.1007/s11079-010-9178-9

Publisher: Springer

All outputs in CentAUR are protected by Intellectual Property Rights law, including copyright law. Copyright and IPR is retained by the creators or other copyright holders. Terms and conditions for use of this material are defined in the End User Agreement.

www.reading.ac.uk/centaur

\section{CentAUR}

Central Archive at the University of Reading

Reading's research outputs online 


\title{
MFN Status and the Choice of Tariff Regime
}

\author{
Nigar Hashimzade* \\ University of Reading \\ Khassan Khodavaisi \\ Urmia University \\ Gareth D. Myles \\ University of Exeter and Institute for Fiscal Studies
}

June 1, 2010

\begin{abstract}
The gradualist approach to trade liberalization views the uniform tariffs implied by MFN status as an important step on the path to free trade. We investigate whether a regime of uniform tariffs will be preferable to discriminatory tariffs when countries engage in non-cooperative interaction in multilateral trade. The analysis includes product differentiation and asymmetric costs. We show that with the cost asymmetry the countries will disagree on the choice of tariff regime. When the choice of import tariffs and export subsidies is made sequentially the uniform tariff regime may not be sustainable, because of an incentive to deviate to a discriminatory regime. Hence, an international body is needed to ensure compliance with tariff agreement.

JEL Classification: F12, F13

Keywords: MFN clause, product differentiation, discriminatory tariffs
\end{abstract}

\section{Introduction}

Imperfectly competitive markets cause a deviation from the efficient outcome and provide a pretext for government intervention. In the trade literature it is now well understood that a country can gain through unilateral intervention in an imperfectly competitive market (see Brander 1995, Brander and Spencer 1984, 1985). According to models of strategic trade policy with immobile but imperfectly competitive firms, there is a welfare gain for a country from shifting rents to the firms in its jurisdiction (by using a subsidy) or to the government (by using a tariff). When several governments simultaneously intervene the outcome can be mutually damaging. One response suggested in the literature to

${ }^{*}$ Corresponding author: School of Economics, University of Reading, Whiteknights, Reading, Berkshire, RG6 6AA, United Kingdom. E-mail: N.Hashimzade@reading.ac.uk.

Acknowledgement: The authors wish to thank the editor and two anonymous referees for their comments and suggestions that helped to greatly improve the paper. 
eliminate the unwelcome distortions caused by such unilateral trade policies is the adoption of free trade since all countries would be better off if none intervened. Reaching such a position could involve significant (and costly) adjustment in many countries so a gradualist approach has much to commend it. An intermediate step on the gradualist path toward creating a free-trade environment is for supranational institutions like GATT/WTO to impose harmonized international rules.

An important example of a harmonized rule is the Most Favored Nation (MFN) clause which is a significant part of all multilateral trade agreements. It has been described by Horn and Mavroidis (2001) and Hoekman and Kostecki (2001) as one of the pillars of the WTO system. At the core of MFN is the idea of non-discrimination or symmetric treatment for all ${ }^{1}$. In other words, if country $A$ grants country $B$ the status of MFN, it simply agrees to treat country $B$ no worse than any other country. Thus, it is natural to enquire into the circumstances in which a country prefers a regime of MFN tariffs to one of tariff discrimination.

There have been several attempts in the literature to address this issue. Gatsios (1990) and Hwang and Mai (1991) investigated optimal discriminatory tariffs imposed by an importing country on two foreign firms located in two distinct exporting countries. They demonstrated that the importing country prefers to impose discriminatory or preferential tariffs, rather than a uniform tariff across different countries, when the supplying firms have different production costs. This occurs because the importing country has two instruments in the discriminatory tariff regime compared with just one instrument with the uniform tariff regime. A further result is that, with discriminatory tariffs, the tariff on the low-cost firm should be higher than that on the high-cost firm since this reduces the total cost (marginal production cost plus specific tariff) differential between imports from different countries. In terms of production efficiency, production is diverted from the more efficient to the less efficient country under a discriminatory tariff regime. The consequences of enforcing a uniform tariff regime by imposing the MFN principle will be an overall gain in production efficiency with distributional effects favoring the cost-efficient country.

It is important to ask whether these conclusions remain valid when the exporting governments also actively engage in trade policy. Liao and Wong (2006) allowed all three governments (the governments of the two exporting countries and that of the importing country) to choose optimal policies that maximize their welfare. For symmetric exporting countries producing perfect substitute goods and engaging in Cournot competition, they found that the importing country would choose a uniform tariff regime, whereas the exporting countries would prefer a discriminatory tariff regime. In a similar setting, Saggi and Yildiz (2005) consider the effect of different cost and market structure, under both Cournot and Bertrand competition between the producers in the exporting

\footnotetext{
${ }^{1}$ Although the GATT/WTO prohibits discriminatory import tariffs, the means for such policy exist within GATT/WTO rules. For example, discriminatory tariffs can be imposed through the enforcement of anti-dumping duty laws. Hence, there are many ways by which the WTO/GATT's ban on discriminatory import tariffs can be and is circumvented.
} 
countries, allowing for product differentiation. In Saggi $(2004,2006)$ and Saggi and Yildiz (2009) the effect of entering an MFN agreement and the endogenous formation of MFN clubs is considered in a model with Cournot competition and segmented markets for a homogenous good when producers differ in cost of production, and all countries produce, import, and export. The main finding, assuming linear demand, is that the high-cost countries refuse reciprocal MFN adoption, while the MFN adoption by the country with average cost production is the most desirable. These are interesting results, but the assumptions of homogenous products leaves open the question of whether they are robust to the introduction of product differentiation.

The contribution of this paper to the literature on optimal trade policy is to extend existing analysis by introducing product differentiation in a multilateral trade setting in which every country produces, trades, and employs active trade policy. We also move away from homogenous products and permit product differentiation. We have explored both Cournot and Bertrand competition (though we only report results for Cournot in this paper). Using this generalized model we analyze the welfare consequences of two different tariff regimes: a uniform tariff regime, as required by the MFN clause of GATT/WTO, and a discriminatory tariff regime. We employ the model to address whether countries still pay an export subsidy to their firms (as proposed by Brander and Spencer (1985), and others) when it is known that the importing party will respond, and whether countries achieve a mutually beneficial outcome by agreeing to constrain their choices through MFN. Our results show that with simultaneous choice of tariffs and export subsidies or with tariffs chosen first, the low-cost country always prefers the uniform regime and the high-cost the discriminatory regime. The preference of a country with intermediate cost level depends on whether it is close to the low cost or the high cost. When the countries differ in cost disagreement on the preferred regime will always arise. The outcome when export subsidies are chosen before tariffs is different: all three countries prefer the uniform regime (unless there is considerable cost divergence between the two higher-cost countries). At first sight this seems to imply that MFN will be implemented under this timing structure. However, after the tariff regime has been announced and the subsidies chosen there is an incentive for each country to renege on the MFN agreement and impose discriminatory tariffs. This finding implies that an international body can play a role in ensuring tariff agreements are respected and provides motivation for the trading partners to make an international commitment to follow an announced tariff regime (such as to follow the MFN clause of GATT/WTO) which cannot be easily changed.

The paper is structured as follows. In section 2 we describe the model used in the paper. In section 3 we derive the equilibrium for the discriminatory tariff regime and the uniform tariff regime when tariffs and subsidies are chosen simultaneously, and provide a welfare comparison of the two tariff regimes. This is undertaken first for symmetric and then for asymmetric production costs. In section 4 a similar analysis is provided for the situations when tariffs and subsidies are chosen sequentially. In section 5 we analyze the credibility of agreement upon tariff regime when the choice of export subsidies is observed 
before the tariffs are set. The main findings are summarized in section 6 . Details of analytical derivations are gathered in the Appendix available online at http://people.exeter.ac.uk/gdmyles/papers/pdfs/MfnStaApp.pdf.

\section{Structure of Model}

The structure of the model is the following: The world economy consists of three countries that produce and trade differentiated products. We refer to country 1 as the home country, and countries 2 and 3 as foreign countries. Each country is host to a single firm, and the home country is distinguished by hosting the firm with the lowest production cost. The three governments understand the structure of the oligopolistic industry and set credible tariffs on imports and taxes or subsidies on exports. The countries determine their policies strategically. Firms can transport their product costlessly, but the markets are assumed to be segmented for consumers.

The governments choose their policy variables (an export subsidy and an import tariff) to maximize the welfare of their countries. We analyze the interactions among the governments as a non-cooperative multi-stage game. In the first stage, the countries announce whether they are using a uniform tariff regime $(U)$ or a discriminatory tariff regime $(D)$. Three different timing structures are considered for the later stages of the game. In game $S$, export subsidies and import tariffs are chosen simultaneously and non-cooperatively. In game $I$, import tariffs are chosen first, and export subsidies are chosen after observing the tariffs. In game $E$, the timing is reversed. The different sequences of moves can be viewed as the difference in timing, or in information structure, between setting internal (subsidy to the domestic firm) and external (tariffs on goods produced abroad) policies. In the final stage of the game, the firms move simultaneously with each firm taking the tariffs and subsidies, as well as the decision of the other firms, as given. All technology and demand information is known to all parties. We derive the equilibrium of the game for the two tariff regimes. The regimes are then compared in terms of the welfare of each country, as well as global welfare defined as the sum of the welfare of all three countries.

The demand side of the model is derived from the utility maximization problem of a representative consumer in each country. We follow the modelling assumptions and notation of Yi (1996). Denote country $i$ 's consumption of the good produced in country $j$ by $q_{i j}$. The utility function of the consumer in country $i$ is then given by

$$
U_{i}=u\left(q_{i 1}, q_{i 2}, q_{i 3}\right)+Z_{i},
$$

where $Z_{i}$ is consumption of a competitive numeraire good that can be costlessly transported across countries. The sub-utility function is

$$
u(\cdot)=a_{i} Q_{i}-\frac{\gamma}{2} Q_{i}^{2}-\frac{1-\gamma}{2} \sum_{i=1}^{3} q_{i j}^{2}, \quad Q_{i}=\sum_{i=1}^{3} q_{i j}, \quad 0 \leq \gamma \leq 1,
$$


where parameter $\gamma \in[0,1]$ captures the extent of product differentiation (see Tirole, 1988). When $\gamma=1$ the products are perfect substitutes. As $\gamma$ decreases the products become less homogenous, and at $\gamma=0$ the demands for the goods are independent. From the utility function the inverse demand functions are

$$
p_{i j}=a_{i}-(1-\gamma) q_{i j}-\gamma Q_{i},
$$

where $p_{i j}$ is the price received in country $i$ for country $j$ 's good.

Firm $i$ has constant marginal cost, $c_{i}$; since we do not deal with the entry of firms, fixed costs are set to zero for simplicity. The level of profit, $\pi_{i}$, for the firm located in country $i$ is

$$
\pi_{i}=\sum_{j=1}^{3}\left(p_{j i}-c_{i}+s_{i j}-t_{j i}\right) q_{j i},
$$

where $s_{i j}$ is the export subsidy imposed by country $i$ for the good exported to country $j$, and $t_{j i}$ is the import tariff imposed by the country $j$ on goods imported from country $i$. Throughout the paper we consider only the case of specific subsidies and tariffs. ${ }^{2}$ The firms can compete by choosing quantities (Cournot) or prices (Bertrand) in each country. We focus upon Cournot competition; the results obtained for Bertrand competition are qualitatively the same and the details are available from the authors upon request. For analytical tractability we consider identical demands $\left(a_{i}=1\right.$ for $\left.i=1,2,3\right)$; it is not difficult to extend the model to the analysis of markets of different sizes (say, $\left.a_{1} \geq a_{2} \geq a_{3}\right)$. To analyze the effect of the cost asymmetry, without loss of generality, we normalize $c_{1}$ to zero and assume that $c_{2} \geq 0$ and $c_{3} \geq 0$.

For some combinations of costs and degree of product differentiation the firms may be driven to corner solutions where their exports to one or more countries are zero. The analysis of later sections restricts attention to permissible cost combinations that ensure all quantities are non-negative in equilibrium. In fact, we choose to focus throughout on interior equilibria in which all quantities traded between countries are strictly positive. We denote the permissible set of non-negative costs that ensure all quantities are positive for a given value of $\gamma$ by $\mathcal{C}(\gamma)$.

Country $i$ chooses its import tariff and export subsidy to maximize the sum of domestic consumer surplus, domestic profit, and revenue

$$
W_{i}=u(\cdot)-\sum_{j=1}^{3} p_{i j} q_{i j}+\pi_{i}+\sum_{j=1}^{3} t_{i j} q_{i j}-\sum_{j=1}^{3} s_{i j} q_{j i} .
$$

Under the discriminatory tariff regime country $i$ can (potentially) impose different tariffs on the imports from its trading partners. Under the uniform tariff regime the tariffs must be the same, so $t_{i}=t_{i j}$ for all $j \neq i$.

\footnotetext{
${ }^{2}$ This is done for analytical simplicity. Note that in the competitive case, specific and ad valorem tariffs lead to the same outcomes, while under imperfect competition they lead to different outcomes.
} 


\section{Simultaneous Choice}

In this section we consider game $S$ in which the countries choose their tariffs and subsidies simultaneously. We determine the equilibrium of the game for the two tariff regimes. The welfare levels of the countries in the regimes are then compared to deduce preferences over regimes.

\subsection{Discriminatory tariff regime}

Solving the game with discriminatory tariffs shows that the equilibrium subsidy on exports from country $i$ to county $j$ is given by

$$
s_{i j}^{D S}=A_{0}^{D S}(\gamma)+A_{1}^{D S}(\gamma) c_{i}+A_{2}^{D S}(\gamma) c_{j}+A_{3}^{D S}(\gamma) c_{k},
$$

where the superscripts $D$ and $S$ denote the discriminatory regime in game $S$. Coefficients $A_{n}^{D S}(\gamma)$ are rational functions of $\gamma$. These functions, and all those that follow, are detailed in the online Appendix. The level of subsidy can also be written $\mathrm{as}^{3}$

$$
s_{i j}^{D S}=-\frac{2(1+\gamma)(2-\gamma)}{2+\gamma} q_{j i}^{D S},
$$

where $q_{j i}^{D S}$ is the quantity exported from $j$ to $i$. Since $0 \leq \gamma \leq 1$ and we work only with costs in the permissible region where $q_{j i}^{D S}>0$, it follows that $s_{i j}^{D S}<0$. The negative value of the subsidy means that all three countries tax their exports. The equilibrium tariff set by country $i$ on imports from county $j$ is

$$
t_{i j}^{D S}=B_{0}^{D S}(\gamma)+B_{1}^{D S}(\gamma) c_{i}+B_{2}^{D S}(\gamma) c_{j}+B_{3}^{D S}(\gamma) c_{k} .
$$

The sign of the tariff depends on the configuration of costs and the product differentiation parameter and it is possible that the countries find it optimal to subsidize imports.

To understand these expressions it is helpful to begin by considering the difference between the export subsidies and the import tariffs that country $i$ applies on trade with countries $j$ and $k$. These differences are given by

$$
\begin{gathered}
s_{i j}^{D S}-s_{i k}^{D S}=-\gamma C_{1}^{D S}(\gamma)\left(c_{j}-c_{k}\right), \\
t_{i j}^{D S}-t_{i k}^{D S}=-C_{2}^{D S}(\gamma)\left(c_{j}-c_{k}\right),
\end{gathered}
$$

where $C_{1}^{D S}(\gamma)>0$ and $C_{2}^{D S}(\gamma)>0$. Thus, when the demands for the differentiated products are independent $(\gamma=0)$ the subsidies on exported goods are equal for any cost differential. Otherwise, exports to the lower-cost foreign country are taxed less heavily than exports to the higher-cost country. In choosing a value for the export subsidy a country has to trade the enhancement of competitiveness (implying a subsidy) against the gain from securing part of the foreign tax base (implying a tax). The finding that export taxes are always imposed shows that the second effect dominates in this model, but the lower tax

${ }^{3}$ The authors are grateful to the anonymous referee for pointing this out. 
on exports to the lower-cost country reflects the need for competitiveness. The tariff imposed on imports from the lower-cost country are higher (or, the subsidies are lower, when imports are subsidized) than that on imports from the high-cost country. As a consequence, the discriminatory tariff policy has the effect of partly equalizing the cost differences between the exporting countries and extracting relatively more of the surplus of the low-cost exporter. It is this feature of the discriminatory tariffs that explains why we find below that the home country (which always has the lowest cost) ultimately prefers the uniform tariff regime.

To explore the structure of tariffs further we separate the analysis into three cases: the policy of the home country, the policy of the foreign countries toward the home country, and the policy between the two foreign countries. Consider first the symmetric case with $c_{2}=c_{3}=c$. With symmetry (2) shows that the tariff set by the home country on imports from country $i$ is

$$
t_{1 i}^{D S}(c)=B_{0}^{D S}(\gamma)+\left[B_{2}^{D S}(\gamma)+B_{3}^{D S}(\gamma)\right] c,
$$

where $B_{2}^{D S}(\gamma)+B_{3}^{D S}(\gamma)<0$, so that at $c=0$ the tariffs can only be positive when $B_{0}^{D S}(\gamma)>0$. Define $\bar{\gamma}^{S}$ by $B_{0}^{D S}\left(\bar{\gamma}^{S}\right)=0$ so that $B_{0}^{D S}(\gamma)>0$ for $\gamma<\bar{\gamma}^{S}$ and $B_{0}^{S}(\gamma)<0$ for $\gamma>\bar{\gamma}^{S}$. ${ }^{4}$ If $c=0$ the tariff is positive if $\gamma<\bar{\gamma}^{S}$ and negative if $\gamma>\bar{\gamma}^{S}$. This pattern for the tariff is also found in the other games so it is worth developing the intuition. The choice of tariff always trades the incentive to subsidize and, hence, reduce monopoly deadweight loss by increasing output against the incentive to tax in order to secure part of the surplus obtained from the exploitation of monopoly power. When the demands are independent (low $\gamma$ ) the firms have greater monopoly power which they employ to secure profit. The positive tariff then has two effects: it gives a country's firm an advantage and allows it to secure relatively more surplus that remains within the country, and it extracts some of the surplus obtained by the importing firms. When the goods are closer substitutes ( $\gamma$ high) there is less surplus to extract so it makes more sense to use a negative tariff that encourages competition and allows the country to increase welfare by reducing deadweight loss.

By continuity, the same conclusions hold for $c$ sufficiently close to zero in the symmetric case, and for $c_{i}, c_{j}$ sufficiently close to zero with a cost asymmetry. Fig. 1 illustrates how the sign of optimal tariffs imposed by the home country on imports from the two foreign countries depends on the configuration of production costs. The set of permissible costs is the area bounded by the two black lines. As $\gamma$ increases the red line $\left(t_{12}^{D S}=0\right)$ and the blue line $\left(t_{13}^{D S}=0\right)$ move toward the origin, so the set of cost parameters, $\left(c_{i}, c_{j}\right)$, for which at least one tariff is positive shrinks. The figure also shows that with symmetric costs for the foreign countries the sign of the optimal tariffs changes from positive to negative (for $\gamma<\bar{\gamma}^{S}$ ) once the production cost exceeds the threshold, $\bar{c}^{D S}$, found from (3)

$$
\bar{c}^{D S}=\frac{B_{0}^{D S}(\gamma)}{-\left[B_{2}^{D S}(\gamma)+B_{3}^{D S}(\gamma)\right]} .
$$

${ }^{4} \bar{\gamma}^{S}$ is defined by $B_{0}^{S}\left(\bar{\gamma}^{S}\right)=0$, so $\bar{\gamma}^{S}=\frac{\sqrt{13}-1}{3} \simeq 0.868$. 
The intuition is that the low-cost country has a worldwide comparative advantage. It finds it beneficial to use some of the surplus generated by this advantage to finance a subsidy that encourages supply to its market and therefore reduce deadweight loss. Clearly, $\bar{c} \leq 0$ for $\gamma \geq \bar{\gamma}^{S}$, and, hence, the optimal tariffs in the symmetric case are negative when the goods are close substitutes.

\section{[INSERT FIG. 1 HERE]}

Now consider the tariffs imposed by the foreign countries on imports from the home country. In the symmetric case,

$$
t_{i 1}^{D S}=B_{0}^{D S}(\gamma)+\left[B_{1}^{D S}(\gamma)+B_{3}^{D S}(\gamma)\right] c .
$$

At $c=0$ the sign of $t_{i 1}^{D S}$ is determined by the sign of $B_{0}^{D S}(\gamma)$ so $t_{i 1}^{D S}(0) \lesseqgtr 0$ iff $\gamma \gtreqless \bar{\gamma}^{S}$. By continuity, the same holds for $c$ sufficiently close to zero in the symmetric case, and for both $c_{2}$ and $c_{3}$ sufficiently close to zero with cost asymmetry. When the production costs are close to each other the countries subsidize imports if the goods are close substitutes and tax imports otherwise. These observations are illustrated in Fig. 2 for $\gamma=1$.

[INSERT FIG. 2 HERE]

Finally, we analyze the interaction between the two foreign countries. With symmetric production costs the expression for tariffs simplifies to

$$
t_{i j}^{D S}(c)=\frac{(2-\gamma)\left(4-2 \gamma-3 \gamma^{2}\right)}{(2+\gamma)(4-\gamma)} q_{j i}^{D S}(c), i, j=1,2,
$$

where $4-2 \gamma-3 \gamma^{2} \gtreqless 0$, and, hence, $t_{i j}^{D S}(c) \gtreqless 0$, iff $\gamma \lesseqgtr \bar{\gamma}^{S}$. The outcome with asymmetric costs is illustrated in Figs. 3 and 4.

\section{[INSERT FIGS. 3 AND 4 HERE]}

This analysis of (2) is summarized in Proposition 1.

Proposition 1 In the discriminatory regime in game $S$ there exists $\bar{\gamma}^{S}$ such that:

1. The signs of tariffs on imports into the home country are determined according to:

(i) if $\gamma>\bar{\gamma}^{S}$ then both tariffs are negative;

(ii) if $\gamma \leq \bar{\gamma}^{S}$ then for $i, j \in\{2,3\}, i \neq j$

$$
t_{1 i}^{D S} \gtreqless 0 \text { iff } c_{i} \lesseqgtr \frac{B_{0}^{D S}(\gamma)}{-B_{2}^{D S}(\gamma)}+\frac{B_{3}^{D S}(\gamma)}{-B_{2}^{D S}(\gamma)} c_{j} .
$$


2. The signs of tariffs on imports from the home country are determined according to:

(i) if $\gamma<\bar{\gamma}^{S}$ then both tariffs are positive;

(ii) if $\gamma \geq \bar{\gamma}^{S}$ then for $i, j \in\{2,3\}, i \neq j$

$$
t_{i 1}^{D S} \gtreqless 0 \text { iff } c_{i} \gtreqless-\frac{B_{0}^{D S}(\gamma)}{B_{1}^{D S}(\gamma)}-\frac{B_{3}^{D S}(\gamma)}{B_{1}^{D S}(\gamma)} c_{j} .
$$

3. The sign of tariffs on imports between the two foreign countries are determined according to:

(i) if $\gamma<\bar{\gamma}^{S}$ then for $i, j \in\{2,3\}, i \neq j$

$$
t_{i j}^{D S} \gtreqless 0 \text { iff } c_{i} \gtreqless-\frac{B_{0}^{D S}(\gamma)}{B_{1}^{D S}(\gamma)}+\frac{-B_{2}^{D S}(\gamma)}{B_{1}^{D S}(\gamma)} c_{j} .
$$

(ii) the converse is true if $\gamma \geq \bar{\gamma}^{S}$.

To summarize, all countries tax their exports. If product differentiation is sufficiently strong, the import tariffs between all pairs of countries are positive when the countries do not differ very much in production costs. When production costs are sufficiently lower in one country compared to the other two, then the low-cost country subsidizes imports from the high-cost countries, while the two high-cost countries tax the imports from the low-cost country and from each other. When the products are close substitutes imports are subsidized by the lower-cost countries and taxed by the higher-cost countries.

\subsection{Uniform tariff regime}

We now analyze the optimal choice of policy under the uniform tariff regime that represents an MFN agreement. Specifically, the home country levies the same tariff on imports from both foreign countries; however, there is no such restriction on export subsidies. The same applies to the foreign countries.

By solving the game we derive the following expression for subsidies

$$
\begin{aligned}
s_{i j}^{U S} & =A_{0}^{U S}(\gamma)+A_{1}^{U S}(\gamma) c_{i}+A_{2}^{U S}(\gamma) c_{j}+A_{3}^{U S}(\gamma) c_{k} \\
& =-\frac{2(1+\gamma)(2-\gamma)}{(2+\gamma)} q_{j i}^{U S},
\end{aligned}
$$

and for tariffs

$$
t_{i}^{U S}=B_{0}^{U S}(\gamma)+B_{1}^{U S}(\gamma) c_{i}+B_{2}^{U S}(\gamma)\left(c_{j}+c_{k}\right) .
$$

The sign of the subsidy is clearly negative, so all three countries tax their exports. The difference between the levels of export taxes applied to countries $j$ and $k$ in the uniform tariff regime is given by

$$
s_{i j}^{U S}-s_{i k}^{U S}=C_{0}^{S}(\gamma)\left(c_{j}-c_{k}\right),
$$


where $C_{0}^{S}(\gamma)>0$. Hence, the exports into a lower-cost country are taxed more heavily than the exports into a higher-cost country. This is opposite to the situation in the discriminatory tariff regime. The intuition for this is that the uniform regime forces the tariff on imports from the lower-cost country to be reduced relative to the tariff on the higher-cost country. This reduces the surplus extracted from the lower-cost country. To offset this effect the export tax on goods going to the lower-cost country is raised. The opposite argument applies to the higher-cost country.

We again separate discussion of the tariffs into an analysis of the policy of the home country and then an analysis of the policies of the foreign countries. From (5) the sign of the uniform tariff for the home country depends on the configuration of costs and the degree of product differentiation. In the symmetric case $\left(c_{i}=c_{j}=c\right)$

$$
t_{1}^{U S}=B_{0}^{U S}(\gamma)+2 B_{2}^{U S}(\gamma) c
$$

where $B_{0}^{U S}(\gamma) \geq 0$ if $0 \leq \gamma \leq \bar{\gamma}^{S}, B_{0}^{U S}(\gamma) \leq 0$ if $\bar{\gamma}^{S} \leq \gamma \leq 1$, and $B_{2}^{U S}(\gamma)<0$. Therefore, the home country's import tariff is negative when the products are close substitutes $\left(\gamma \geq \bar{\gamma}^{S}\right)$. Otherwise, under weaker substitutability $\left(\gamma \leq \bar{\gamma}^{S}\right)$ the tariff is positive for $c$ sufficiently small and changes sign to negative when $c$ exceeds the threshold

$$
\bar{c}^{U S}=\frac{B_{0}^{U S}(\gamma)}{-2 B_{2}^{U S}(\gamma)}
$$

The effect of cost asymmetry is illustrated in Fig. 5 for $\gamma=0.5$. The figure shows that the sign of the uniform tariff is the same as those of the discriminatory tariff when both foreign countries have low costs or high costs. When one foreign country is high cost and the other low cost the uniform tariff averages the discriminatory tariffs.

[INSERT FIG. 5 HERE]

Now consider the optimal tariffs imposed by a foreign country. In the symmetric case, country $i$ 's optimal tariff is given by

$$
t_{i}^{U S}(c)=B_{0}^{U S}(\gamma)+\left[B_{1}^{U S}(\gamma)+B_{2}^{U S}(\gamma)\right] c .
$$

The coefficient on $c$ in (6) is negative (positive) when $\gamma$ is below (above) $\widetilde{\gamma}^{S}$, where $\widetilde{\gamma}^{S}$ is defined by $B_{1}^{U S}\left(\widetilde{\gamma}^{S}\right)+B_{2}^{U S}\left(\widetilde{\gamma}^{S}\right)=0 .{ }^{5}$ Thus, for $0<\gamma<\widetilde{\gamma}^{S}$ the tariff is positive as long as $c<\widetilde{c}^{U S}(\gamma)=\frac{B_{0}^{U E}(\gamma)}{-\left[B_{1}^{U E}(\gamma)+B_{2}^{U E}(\gamma)\right]}$, and, since $\widetilde{c}^{U S}(\gamma) \geq 2$ is outside the permissible set, the tariff is positive. For $\widetilde{\gamma}^{S}<\gamma<\bar{\gamma}^{S}$ the tariff is also positive for all $c$. Finally, for $\bar{\gamma}^{S}<\gamma<1$ the tariff is negative at $c=0$ and changes sign from negative to positive when cost exceeds the threshold $\widetilde{c}^{U S}(\gamma)$. Hence, when the products substantially differ the tariff is positive for

\footnotetext{
${ }^{5}$ The value of $\widetilde{\gamma}^{S} \simeq 0.34$, so $\widetilde{\gamma}^{S}<\bar{\gamma}^{S}$.
} 
any value of $c$. When the products are close substitutes the tariff is positive for higher costs and negative for lower costs.

In the general case with a cost asymmetry the results are obtained directly from the analysis of (5). As shown in the online Appendix, as long as $\gamma$ is sufficiently small $\left(0 \leq \gamma<\widehat{\gamma}^{S}\right)$ the locus of points $\left\{\left(c_{i}, c_{j}\right): t_{i}^{U S}\left(c_{i}, c_{j}, \gamma\right)=0\right\}$ is outside $\mathcal{C}^{U S}(\gamma)$ and the tariff is positive for all $\left(c_{i}, c_{j}\right) \in \mathcal{C}^{U S}(\gamma)$. The value of $\widehat{\gamma}^{S}$ is determined by solving $\left\{t_{i}^{U S}=0, q_{i, j}^{U S}=0\right\}$ at $c_{j}=0 .{ }^{6}$ For every value of $\gamma$ above the threshold, $\widehat{\gamma}^{S}$, the tariff can be either positive or negative, depending upon the configuration of costs. The signs of the import tariffs for three cases $\left(\gamma<\widehat{\gamma}^{S}, \bar{\gamma}^{S}>\gamma>\widehat{\gamma}^{S}\right.$, and $\left.\gamma>\bar{\gamma}^{S}\right)$ chosen by the countries in the uniform regime are shown in Figs. 6-8, along with those in the discriminatory regime, for comparison. These results are summarized in Proposition 2.

Proposition 2 In the uniform regime in game $S$ there exist $\left\{\widehat{\gamma}^{S}, \bar{\gamma}^{S}\right\}, 0<$ $\widehat{\gamma}^{S}<\bar{\gamma}^{S}<1$, such that:

1. The sign of tariff on imports into the home country is determined according to:

(i) if $\gamma>\bar{\gamma}^{S}$ then the tariff is negative;

(ii) if $\gamma \leq \bar{\gamma}^{S}$ then for $i, j \in\{2,3\}, i \neq j$

$$
t_{1}^{U S} \gtreqless 0 \text { iff } c_{i} \lesseqgtr \frac{B_{0}^{U S}(\gamma)}{-B_{2}^{U S}(\gamma)}-c_{j} ;
$$

2. The sign of tariffs on imports into the foreign countries is determined according to:

(i) if $\gamma<\widehat{\gamma}^{S}$ then the tariffs set by both foreign countries are positive;

(ii) if $\gamma \geq \widehat{\gamma}^{S}$ then for $i, j \in\{2,3\}, i \neq j$

$$
t_{i}^{U S} \gtreqless 0 \text { iff } c_{i} \gtreqless \frac{-B_{2}^{U S}(\gamma)}{B_{1}^{U S}(\gamma)} c_{j}-\frac{B_{0}^{U S}(\gamma)}{B_{1}^{U S}(\gamma)} .
$$

[INSERT FIGS. 6-8 HERE]

\subsection{Welfare comparison}

The welfare levels of the three countries under the two tariff regimes are now compared. The intention is to relate the preferences of the countries over the alternative regimes to the level of cost.

As a first step consider the difference between the optimal policies in the two regimes. For the optimal subsidies we have

$$
s_{i j}^{U S}-s_{i j}^{D S}=C_{1}^{S}(\gamma)\left(c_{i}-c_{k}\right),
$$

${ }^{6}$ The actual value is $\hat{\gamma}^{S}=\frac{\sqrt{11 / 3}-1}{2} \simeq 0.457$. 
and for the optimal tariffs

$$
t_{i}^{U S}-t_{i j}^{D S}=C_{2}^{S}(\gamma)\left(c_{j}-c_{k}\right)
$$

where $C_{1}^{S}(\gamma)>0$ and $C_{2}^{S}(\gamma)>0$. The difference between the subsidies in the two regimes depends upon the position of the country in the cost ranking. In the case of the home country (which has the lowest cost) the export tax is higher under the uniform regime than the discriminatory regime. This is because the export tax is being used in the uniform regime to compensate for the inability to discriminate in the level of tariff. For all three countries the tariff in the uniform regime is averaging the tariffs used in the discriminatory regime, and the sign of the differences follows accordingly.

With identical production costs in the foreign countries $\left(c_{2}=c_{3}=c\right)$ the difference between the home country's welfare levels in the two regimes is given by

$$
W_{1}^{U S}-W_{1}^{D S}=Z_{1}^{S}(\gamma) c+Z_{2}^{S}(\gamma) c^{2}
$$

where $Z_{1}^{S}(\gamma)>0$ and $Z_{2}^{S}(\gamma)>0$. Hence, the home country strictly prefers the uniform tariff regime if foreign marginal cost $c>0$. If the production cost in the two other countries is zero then import tariffs and export subsidies are identical in the two regimes, as is the welfare level of the home country. For the foreign countries the differences in the welfare levels are given by

$$
W_{i}^{U S}-W_{i}^{D S}=Z_{3}^{S}(\gamma) c+Z_{4}^{S}(\gamma) c^{2}, \quad i=2,3 .
$$

The expression on the right-hand side is negative, which implies that the foreign countries strictly prefer the discriminatory tariff regime whenever production cost is strictly positive.

With cost asymmetry the lowest-cost country again prefers the uniform regime. The preference of the higher-cost countries depend on how much their production costs differ. ${ }^{7}$ Intuitively, a continuity argument implies that if the production costs in the foreign countries are relatively high and close to each other, then both prefer the discriminatory regime. If the costs differ substantially the country with lower cost will be better off under the uniform regime. This is illustrated in Fig. 9 for $\gamma=0.5$.

\section{[INSERT FIG. 9 HERE]}

The explanation for these preferences is found in the fact that in the discriminatory regime the equilibrium tariffs partially equalize the differences in production cost. This process is always to the disadvantage of the low-cost country. The equalization cannot occur in the uniform regime, so the lowcost country naturally prefers the MFN regime. In contrast, for precisely the

\footnotetext{
${ }^{7}$ The exact expression describing the switch of preferences in game $S$, as well as in games $I$ and $E$ described in the rest of the paper, is rather cumbersome. The derivations are available from authors upon request.
} 
converse reasons, the higher-cost countries are united in preferring the discriminatory regime when their costs are not too dissimilar. When their costs are dissimilar the discriminatory tariffs will work against the lower-cost of the two countries, so it is this country that will switch preference to the uniform regime.

Global welfare, defined as the sum of the welfare levels of the three countries, is higher under the uniform tariff regime for all permissible costs and any degree of product differentiation. The increase in global welfare is explained by the fact that discriminatory tariffs shift production to high-cost countries so enhance production inefficiency. Moving to uniform tariffs eliminates this effect.

Proposition 3 With simultaneous choice of import tariffs and export subsidies: (1) The country with the lowest production cost always prefers the uniform tariff regime.

(2) When the production costs in the higher-cost countries are identical both prefer the discriminatory tariff regime.

(3) When the production costs differ substantially, only the highest-cost country prefers the discriminatory regime.

(4) Global welfare is always higher under the uniform regime.

\section{Sequential Choice}

In the previous section we analyzed the simultaneous choice of import tariffs and export subsidies. It is important to consider alternative timing structures to ensure the robustness of the results. We now analyze games $I$ and $E$ in which the choice of tariffs and subsidies is made sequentially.

\subsection{Tariffs set before subsidies}

In game $I$ the countries first set import tariffs. Having observed the chosen import tariffs, the countries then choose their export subsidies. As we shall see, this timing structure delivers results that are only slightly different from those obtained in the setting with simultaneous choice.

Solving the game from the final stage, the export subsidies in the discriminatory tariff regime are given by

$$
\begin{aligned}
s_{i j}^{D I} & =A_{0}^{D I}(\gamma)+A_{1}^{D I}(\gamma) c_{i}+A_{2}^{D I}(\gamma) c_{j}+A_{3}^{D I}(\gamma) c_{k} \\
& =-\frac{2(1+\gamma)(2-\gamma)}{2+\gamma} q_{j i}^{D I} .
\end{aligned}
$$

Thus, in the permissible set with positive quantities the export subsidies are always negative. The equilibrium tariff levied by country $i$ on imports from country $j$ is

$$
t_{i j}^{D I}=B_{0}^{D I}(\gamma)+B_{1}^{D I}(\gamma) c_{i}+B_{2}^{D I}(\gamma) c_{j}+B_{3}^{D I}(\gamma) c_{k}
$$


The differences in the subsidies and tariffs between pairs of countries are

$$
\begin{aligned}
s_{i j}^{D I}-s_{i k}^{D I} & =-C_{1}^{D I}(\gamma) \gamma\left(c_{j}-c_{k}\right), \\
t_{i j}^{D I}-t_{i k}^{D I} & =-C_{2}^{D I}(\gamma)\left(c_{j}-c_{k}\right),
\end{aligned}
$$

where $C_{1}^{D I}(\gamma)>0$ and $C_{2}^{D I}(\gamma)>0$. The qualitative properties of these difference are the same as in game $S$ : when the demands for the differentiated products are independent the subsidies (or, indeed, taxes) on exported goods are equal, for any cost differential. Otherwise, exports to a lower-cost foreign country are taxed less heavily than exports to the higher-cost country and the tariff imposed on imports from a lower-cost country is higher.

As before, we consider the choices of the home country and the foreign countries separately. In the symmetric case the expression for the tariff levied by the home country on exports to the foreign countries can be written as

$$
t_{1 i}^{D I}=B_{0}^{D I}(\gamma)+2 B_{2}^{D I}(\gamma) c .
$$

Since $B_{0}^{D I}(\gamma)>0$ and $B_{2}^{D I}(\gamma)<0$, the sign of the tariff will change as $c$ increases:

$$
t_{1 i}^{D I}(c) \gtreqless 0 \text { iff } c \lesseqgtr \bar{c}^{D I} \equiv \frac{B_{0}^{D I}(\gamma)}{-2 B_{2}^{D I}(\gamma)} .
$$

For all values of $\gamma$ the pairs $\left\{\bar{c}^{D I}, \bar{c}^{D I}\right\}$ are in the permissible set, so in the symmetric case the home country's tariff always changes sign from positive to negative as $c$ increases. The tariff on imports from the home country in the case of symmetric costs is given by

$$
t_{i 1}^{D I}(c)=B_{0}^{D I}(\gamma)+\left[B_{1}^{D I}(\gamma)+B_{3}^{D I}(\gamma)\right] c .
$$

All terms on the right-hand side are positive, which ensures the tariff is always positive. The expression for the tariffs on imports between the foreign countries can be re-written as

$$
t_{i j}^{D I}(c)=\frac{(2-\gamma)\left(12+2 \gamma-4 \gamma^{2}\right)}{(2+\gamma)(4-\gamma)} q_{j i}^{D I}(c),
$$

and, therefore, in the symmetric case the import tariffs between the foreign countries are also positive.

The general case, with asymmetric costs, is described in Proposition 4.

Proposition 4 In the discriminatory regime in game I:

1. The sign of tariffs levied by the home country on imports from foreign country $i$ is determined according to

$$
t_{1 i}^{D I}(c) \gtreqless 0 \text { iff } c_{i} \lesseqgtr \frac{B_{0}^{D I}(\gamma)}{-B_{2}^{D I}(\gamma)}+\frac{B_{3}^{D I}(\gamma)}{-B_{2}^{D I}(\gamma)} c_{j},
$$

for $i, j \in\{2,3\}, i \neq j$.

2. The tariffs levied by the foreign countries on imports from the home country 
are positive.

3. The sign of the tariffs levied by foreign country $i$ on imports from foreign country $j$ is determined according to

$$
t_{i j}^{D I} \gtreqless 0 \text { iff } c_{i} \gtreqless-\frac{B_{0}^{D I}(\gamma)}{B_{1}^{D I}(\gamma)}+\frac{-B_{2}^{D I}(\gamma)}{B_{1}^{D I}(\gamma)} c_{j},
$$

for $i, j \in\{2,3\}, i \neq j$. In particular, both tariffs are positive when the production costs are equal.

In the uniform tariff regime in game $I$ the equilibrium export subsidy is

$$
\begin{aligned}
s_{i j}^{U I} & =A_{0}^{U I}(\gamma)+A_{1}^{U I}(\gamma) c_{i}+A_{2}^{U I}(\gamma) c_{j}+A_{3}^{U I}(\gamma) c_{k} \\
& =-\frac{2(1+\gamma)(2-\gamma)}{(2+\gamma)} q_{i j}^{U I}<0,
\end{aligned}
$$

and the expression for the uniform tariff chosen by country $i$ is

$$
t_{i}^{U I}=B_{0}^{U I}(\gamma)+B_{1}^{U I}(\gamma) c_{i}+B_{2}^{U I}(\gamma)\left(c_{j}+c_{k}\right) .
$$

The analysis of the tariffs is given in Proposition 5.

Proposition 5 In the uniform regime in game $I$ :

1. The sign of the tariff levied by the home country on imports from the foreign countries is determined according to

$$
t_{1}^{U I} \gtreqless 0 \text { iff } c_{i} \lesseqgtr \frac{B_{0}^{U I}(\gamma)}{-B_{2}^{U I}(\gamma)}-c_{j},
$$

for $i, j \in\{2,3\}, i \neq j$.

2. The tariffs levied by both foreign countries are positive.

The differences in import tariffs and export subsidies between the discriminatory and the uniform tariff regimes are given by

$$
\begin{aligned}
s_{i j}^{U I}-s_{i j}^{D I} & =C_{1}^{I}(\gamma)\left(c_{i}-c_{k}\right), \\
t_{i}^{U I}-t_{i j}^{D I} & =C_{2}^{I}(\gamma)\left(c_{j}-c_{k}\right),
\end{aligned}
$$

where $C_{0}^{I}(\gamma)>0, C_{1}^{I}(\gamma)>0$, and $C_{2}^{I}(\gamma)>0$. These results have similar qualitative properties to those for the game $S$ so the tariff on imports into a higher cost country is larger under the uniform regime. The welfare comparison between the different regimes is the same as with the simultaneous choice, described in Proposition 3. Hence:

Proposition 6 The preferences of the countries over tariff regimes in game I are the same as in game $S$, as described in Proposition 3. 


\subsection{Subsidies set before tariffs}

We now analyze the equilibrium in game $E$. In the first stage the tariff regime is announced. In the second stage each country chooses its export subsidy. The countries move simultaneously, each taking the export subsidy of its competitor as given but being aware of how the choice of subsidy will subsequently affect the tariffs. In the final stage, the countries simultaneously and non-cooperatively choose the tariffs, taking the export subsidies as given.

Solving the game shows that the equilibrium export subsidies in the discriminatory tariff regime are

$$
\begin{aligned}
s_{i j}^{D E} & =A_{0}^{D E}(\gamma)+A_{1}^{D E}(\gamma) c_{i}+A_{2}^{D E}(\gamma) c_{j}+A_{3}^{D E}(\gamma) c_{k} \\
& =-\frac{2(3-\gamma)\left(6+2 \gamma-\gamma^{2}\right)}{12-\gamma^{2}} q_{j i}^{D E} .
\end{aligned}
$$

The subsidies are always negative. The equilibrium tariffs are given by

$$
t_{i j}^{D E}=B_{0}^{D E}(\gamma)+B_{1}^{D E}(\gamma) c_{i}+B_{2}^{D E}(\gamma) c_{j}+B_{3}^{D E}(\gamma) c_{k},
$$

where $B_{1}^{D E}(\gamma) \geq 0, B_{2}^{D E}(\gamma)<0$, and $\frac{B_{3}^{D E}(\gamma)}{B_{0}^{D E}(\gamma)} \geq 0$.

In the symmetric case, with $c_{2}=c_{3}=c$, the tariffs imposed by the home country become

$$
t_{1 i}^{D E}(c)=B_{0}^{D E}(\gamma)+\left[B_{2}^{D E}(\gamma)+B_{3}^{D E}(\gamma)\right] c .
$$

Since $B_{2}^{D E}(\gamma)+B_{3}^{D E}(\gamma)<0$, the outcome is determined by the sign of $B_{0}^{D E}(\gamma)$, which is positive for $0 \leq \gamma<\bar{\gamma}^{E}$ and negative for $\bar{\gamma}^{E}<\gamma \leq 1{ }^{8}$ Hence, when $\gamma$ is above $\bar{\gamma}^{E}$ the tariff is negative. When $\gamma$ is below $\bar{\gamma}^{E}$, the home country's tariff is positive at $c=0$, and by continuity remains positive as $c$ increases up to a threshold, $\bar{c}^{D E}$, defined by

$$
\bar{c}^{D E}=\frac{-B_{0}^{D E}(\gamma)}{B_{2}^{D E}(\gamma)+B_{3}^{D E}(\gamma)} .
$$

The tariff is negative for $c>\bar{c}^{D E}$. For the tariffs imposed by the foreign countries on imports from the home country we have

$$
t_{i 1}^{D E}(c)=B_{0}^{D E}(\gamma)+\left[B_{1}^{D E}(\gamma)+B_{3}^{D E}(\gamma)\right] c .
$$

The coefficient on $c$ is positive, and therefore the tariff is positive for $0 \leq \gamma<\bar{\gamma}^{E}$. For $\bar{\gamma}^{E}<\gamma \leq 1$ the tariff is negative for $c$ below a threshold, $\widetilde{c}^{D E}$, defined by

$$
\widetilde{c}^{D E}=\frac{-B_{0}^{D E}(\gamma)}{B_{1}^{D E}(\gamma)+B_{3}^{D E}(\gamma)},
$$

\footnotetext{
${ }^{8} \bar{\gamma}^{E}$ solves $B_{0}^{D E}\left(\bar{\gamma}^{E}\right)=0$, so $\bar{\gamma}^{E} \simeq 0.651$.
} 
and is positive for $c$ above this value. The tariffs on imports between foreign countries in the symmetric case can be written as

$$
t_{i j}^{D E}(c)=\frac{48-84 \gamma+8 \gamma^{2}+14 \gamma^{3}-3 \gamma^{4}}{(4-\gamma)\left(12-\gamma^{2}\right)} q_{j i}^{D E}(c) .
$$

The expression in the numerator is negative (positive) when $\gamma$ is above (below) $\bar{\gamma}^{E}$. Therefore, with cost symmetry the tariffs on imports between the two foreign countries are positive for $0 \leq \gamma<\bar{\gamma}^{E}$ and negative for $\bar{\gamma}^{E}<\gamma \leq 1$. These properties are qualitatively identical to those established for game $S$ and are summarized in Proposition 7.

Proposition 7 In the discriminatory regime in game $E$ there exists $\bar{\gamma}^{E}$ such that:

1. The sign of the tariff levied by the home country on imports from foreign country $i$ is determined according to:

(i) if $\gamma>\bar{\gamma}^{E}$ then both tariffs are negative;

(ii) if $\gamma \leq \bar{\gamma}^{E}$ then for $i, j \in\{2,3\}, i \neq j$

$$
t_{1 i}^{D E} \gtreqless 0 \text { iff } c_{i} \lesseqgtr \frac{B_{0}^{D E}(\gamma)}{-B_{2}^{D E}(\gamma)}+\frac{B_{3}^{D E}(\gamma)}{-B_{2}^{D E}(\gamma)} c_{j} .
$$

2. The sign of the tariff levied by foreign country $i$ on imports from the home country is determined according to:

(i) if $\gamma<\bar{\gamma}^{E}$ then both tariffs are positive;

(ii) if $\gamma \geq \bar{\gamma}^{E}$ then for $i, j \in\{2,3\}, i \neq j$

$$
t_{i 1}^{D E} \gtreqless 0 \text { iff } c_{i} \gtreqless \frac{-B_{0}^{D E}(\gamma)}{B_{1}^{D E}(\gamma)}+\frac{-B_{3}^{D E}(\gamma)}{B_{1}^{D E}(\gamma)} c_{j} .
$$

3. The sign of the tariff levied by foreign country $i$ on imports from foreign country $j$ is determined according to

$$
t_{i j}^{D E} \gtreqless 0 \text { iff } c_{i} \gtreqless-\frac{B_{0}^{D E}(\gamma)}{B_{1}^{D E}(\gamma)}+\frac{-B_{2}^{D E}(\gamma)}{B_{1}^{D E}(\gamma)} c_{j},
$$

for $i, j \in\{2,3\}, i \neq j$.

In the uniform tariff regime the equilibrium subsidy set by country $i$ on exports to country $j$ is

$$
\begin{aligned}
s_{i j}^{U E} & =A_{0}^{U E}(\gamma)+A_{1}^{U E}(\gamma) c_{i}+A_{2}^{U E}(\gamma) c_{j}+A_{3}^{U E}(\gamma) c_{k} \\
& =-\frac{2(2-\gamma) R^{E}(\gamma)}{10-\gamma^{2}} q_{j i}^{U E} .
\end{aligned}
$$

The equilibrium export subsidies are always negative. The difference between the two subsidies to countries $j$ and $k$ is

$$
s_{i j}^{U E}-s_{i k}^{U E}=C_{0}^{E}(\gamma)\left(c_{j}-c_{k}\right)
$$


where $C_{0}^{E}(\gamma)>0$. As in the previous games, in the uniform tariff regime the exports to a lower-cost country are taxed less than those to a higher-cost country. The equilibrium value of the uniform tariff set by country $i$ is

$$
t_{i}^{U E}=B_{0}^{U E}(\gamma)+B_{1}^{U E}(\gamma) c_{i}+B_{2}^{U E}(\gamma)\left(c_{j}+c_{k}\right)
$$

where $B_{1}^{U E}(\gamma) \geq 0$ and $B_{2}^{U E}(\gamma)<0$. For the uniform tariff set by the home country from (7) we obtain

$$
t_{1}^{U E}=B_{0}^{U E}(\gamma)+B_{2}^{U E}(\gamma)\left(c_{i}+c_{j}\right)
$$

$B_{0}^{U E}(\gamma)$ is positive (negative) when $\gamma$ is below (above) $\widehat{\gamma}^{E}$ defined by $B_{0}^{U E}\left(\widehat{\gamma}^{E}\right)=$ $0 .{ }^{9}$ Therefore, $t_{1}^{U E}$ is non-positive when $\widehat{\gamma}^{E} \leq \gamma \leq 1$; otherwise, it is positive for smaller costs and negative for larger costs.

When production costs in the two foreign countries are equal $\left(c_{i}=c_{j}=c\right)$ the uniform tariff set by the foreign countries are

$$
t_{i}^{U E}=B_{0}^{U E}(\gamma)+\left[B_{1}^{U E}(\gamma)+B_{2}^{U E}(\gamma)\right] c .
$$

The coefficient on $c$ in (8) is negative (positive) when $\gamma$ is below (above) $\widetilde{\gamma}^{E}$ defined by $B_{1}^{U E}\left(\widetilde{\gamma}^{E}\right)+B_{2}^{U E}\left(\widetilde{\gamma}^{E}\right)=0 .{ }^{10}$ Thus, for $0<\gamma<\widetilde{\gamma}^{E}$ the tariff is positive as long as $c<\bar{c}^{E}(\gamma)=\frac{-B_{0}^{U E}(\gamma)}{B_{1}^{U E}(\gamma)+B_{2}^{U E}(\gamma)}$, and, since $\bar{c}^{U E}(\gamma) \geq 2$ is outside the permissible set, the tariff is positive. For $\widetilde{\gamma}^{E}<\gamma<\widehat{\gamma}^{E}$ the tariff is also positive for all $c$, since on this interval all coefficients in the right-hand side of (8) are positive. Finally, for $\widehat{\gamma}^{E}<\gamma<1$ the tariff is negative at $c=0$ and changes sign from negative to positive as cost increases above the threshold $\bar{c}^{U E}(\gamma)$. In particular, when demands for the products are highly independent the tariff is positive for any value of $c$. When the products are close substitutes the tariff is positive for higher costs and negative for lower costs. The general analysis is given in Proposition 8. The situation is essentially similar to the one in game $S$. In particular, the tariffs levied by the foreign countries are positive for small $\gamma$, whereas when the goods are close substitutes ( $\gamma$ is above the threshold, $\gamma^{* E}$, defined by solving $\left\{t_{i}^{U E}=0, q_{i j}^{U E}=0\right\}$ for $\left.c_{j}=0, i, j=2,3\right)$ the tariffs can be either positive or negative, depending on the configuration of parameters.

Proposition 8 In the uniform regime in game $E$ there exist $\left\{\gamma^{* E}, \widehat{\gamma}^{E}\right\}: 0<$ $\gamma^{* E}<\widehat{\gamma}^{E}<1$ such that:

1. The sign of the tariff levied by the home country is determined according to:

(i) if $\gamma>\widehat{\gamma}^{E}$ then $t_{1}^{U E}<0$;

(ii) if $\gamma \leq \widehat{\gamma}^{E}$ then for $i, j \in\{2,3\}, i \neq j$

$$
t_{1}^{U E} \gtreqless 0 \text { iff } c_{i} \lesseqgtr \frac{B_{0}^{U E}(\gamma)}{-B_{2}^{U E}(\gamma)}-c_{j} .
$$

\footnotetext{
${ }^{9}$ The value of $\widehat{\gamma}^{E} \simeq 0.80$.

${ }^{10}$ The value of $\widetilde{\gamma}^{E} \simeq 0.32$.
} 
2. The tariff levied by both foreign countries is determined according to:

(i) if $\gamma<\gamma^{* E}$ then the tariffs set by both foreign countries are positive;

(ii) if $\gamma \geq \gamma^{* E}$ then for $i, j \in\{2,3\}, i \neq j$

$$
t_{i}^{U E} \gtreqless 0 \text { iff } c_{i} \gtreqless \frac{-B_{2}^{U E}(\gamma)}{B_{1}^{U E}(\gamma)} c_{j}-\frac{B_{0}^{U E}(\gamma)}{B_{1}^{U E}(\gamma)} .
$$

The difference between the export subsidies and import tariffs under two regimes is given by

$$
\begin{aligned}
s_{i j}^{U E}-s_{i j}^{D E} & =G_{0}^{E}(\gamma)+G_{1}^{E}(\gamma) c_{i}+G_{2}^{E}(\gamma) c_{i}+G_{3}^{E}(\gamma) c_{i}, \\
t_{i}^{U E}-t_{i j}^{D E} & =H_{0}^{E}(\gamma)+H_{1}^{E}(\gamma) c_{i}+H_{2}^{E}(\gamma) c_{i}+H_{3}^{E}(\gamma) c_{i} .
\end{aligned}
$$

The difference between this case and the previous two cases (games $S$ and $I$ ) is that the differences in the export subsidies and import tariffs between the regimes depend on the production costs in all three countries. They can therefore be positive or negative for different combinations of parameters. Further analysis reveals the following. (1) The export tax imposed by the home country is higher under the uniform regime for any cost differential between the foreign countries, whereas the import tariff is higher under the uniform regime when the two foreign countries have identical costs. When costs are sufficiently different the tariff on imports in the lower-cost foreign country is lower under the uniform regime; the converse is for the higher-cost foreign country. (2) In the symmetric case, the tariff on imports from the home country into a foreign country are higher under the uniform regime when the cost is low, and lower when the cost is sufficiently high; the same is true for export taxes. With cost asymmetry in the foreign countries, the tariff on import from a home country into a foreign country is higher under the uniform regime when the production cost in the other foreign country is low, and is higher under the discriminatory regime when the production cost in the other foreign country is sufficiently high. The same is true for export taxes. (3) The export taxes and import tariffs on trade between the two foreign countries are always higher under the uniform regime than the discriminatory regime.

The difference in outcome between this game and games $S$ and $I$ is a direct consequence of the timing structure. The key feature of game $E$ is that the subsidies can be used strategically to affect the tariffs that are chosen in the next stage. The strategic effect of the subsidies is important in both the discriminatory and the uniform regimes. In the discriminatory regime the tariffs partially equalize costs, so reduce the competitive advantage of the low-cost country. The countervailing effect of the subsidy is then especially important for the low-cost country. Equally, in the uniform regime the countries lose one degree of freedom in their policy choice so the subsidies are used to compensate for this loss.

The welfare levels of the three countries under the two tariff regimes are now compared. This is first undertaken for the case of symmetric production 
costs in the foreign countries and then for the case of asymmetric costs. The difference in the welfare levels of the home country under the two regimes when $c_{i}=c_{j}=c$ is given by a quadratic polynomial in $c$

$$
W_{1}^{U E}-W_{1}^{D E}=A_{1}(\gamma) c^{2}+A_{2}(\gamma) c+A_{3}(\gamma) .
$$

The coefficients satisfy $A_{1}(\gamma)>0, A_{2}(\gamma)<0, A_{3}(\gamma)>0$, and $A_{2}(\gamma)^{2}-$ $4 A_{1}(\gamma) A_{3}(\gamma)<0$. Therefore, this expression is strictly positive, which implies that the home country always prefers the uniform tariff regime when the production costs in the foreign countries are identical. For the foreign countries

$$
W_{i}^{U E}-W_{i}^{D E}=B_{1}(\gamma) c^{2}+B_{2}(\gamma) c+B_{3}(\gamma),
$$

where $B_{1}(\gamma)>0, B_{2}(\gamma)<0, B_{3}(\gamma)>0$, and $B_{2}(\gamma)^{2}-4 B_{1}(\gamma) B_{3}(\gamma)<0$. This expression is strictly positive for small values of $c$, and switches sign from positive to negative when $c$ exceeds a threshold value. This is different from the welfare outcome in games $S$ and $I$ : now in the symmetric case all three countries prefer the uniform regime in a substantial subset of the permissible set of costs for any degree of product differentiation. The foreign countries prefer the discriminatory regime only when costs are sufficiently high.

With cost asymmetry the home country's welfare is again higher under the uniform regime than the discriminatory regime. The preferences of the foreign countries differ when the cost differential between them is sufficiently large. These observations are illustrated in Fig. 10 which shows how the preferences of the three countries depend on the configuration of costs when the demands for goods are independent, i.e. for $\gamma=0$. For larger values of $\gamma$ the picture is very similar, but the area of disagreement on the uniform regime is smaller.

[INSERT FIG. 10 HERE]

\section{Credibility of the announced policy}

We have shown that when the import tariffs and export subsidies are chosen simultaneously, or the import tariffs are chosen before export subsidies, the country with the lowest production cost is always better off under the uniform tariff regime while the countries with relatively high production costs are better off under the discriminatory regime. The disagreement about the choice of regime arises for a substantial set of parameter values. The situation when import tariffs are chosen after export subsidies is different: all three countries prefer the uniform regime, unless one (or both) foreign countries has a very high production cost.

It might seem that these observations suggest there are stronger grounds for expecting the implementation of an MFN agreement when tariffs are chosen after subsidies. However, there is an additional issue that has to be addressed 
before this claim can be asserted. The ordering of moves raises the possibility that after the tariff regime (uniform or discriminatory) is announced and the export subsidies have been chosen and observed, the countries may reconsider their choice of tariffs and deviate from the announced regime. The countries will renege on the agreement to a tariff regime if this is beneficial. This possibility does not arise when tariffs and subsidies are chosen simultaneously, or when tariffs are chosen first.

We now show that, indeed, having announced the uniform tariff regime each country has an incentive to deviate to the discriminatory regime after the export subsidies are chosen, unless the production costs in two other countries are identical (in which case the tariffs chosen under the two regimes coincide). The central result concerning the credibility of the announcement of a uniform regime are summarized in the next proposition.

Proposition 9 When export subsidies are chosen first then the agreement on the uniform regime is not sustainable:

(i) Each country has an individual incentive to deviate to the discriminatory regime.

(ii) A deviation by one country benefits the higher-cost non-deviating country.

(iii) The welfare of the low-cost non-deviating country and global welfare fall as a result of such deviation.

It is not surprising that there is an incentive to deviate. Under the discriminatory regime a country has two import policy instruments, whereas under the uniform regime it has only one. An alternative way of viewing this is that the uniform regime is the discriminatory with an additional constraint on the choice of tariffs. If other countries choose the uniform regime then the additional flexibility of the discriminatory regime is always going to prove appealing.

\section{Conclusions}

We have addressed the question of whether trading partners can achieve a mutually beneficial outcome by following the MFN principle which involves an importing country applying the same tariff to all imports from all exporting countries. This principle is part of all multilateral trading agreements. The MFN principle is seen as reducing distortions in trading patterns and providing an important step on the path to liberalized trade. Moreover, it is usually seen as being in the interest of a developing country to secure MFN status from a developed country. The central component of our analysis is to embed MFN within a model of strategic trade policy to investigate how it interacts with other trade policies.

We have modelled trade policy in a discriminatory regime, in which tariffs can vary on imports from different countries, and in a uniform regime where MFN applies and a single tariff is levied on all imports. We have also considered three timing structures for the trade policy game. For each game we have determined the optimal trade policy in the two regimes when countries act 
strategically in choosing their policy instruments and used this to construct preferences over tariff regimes. In every situation there has always been a lowcost country and two others that may higher costs. The equilibrium outcomes have been related to the degree of substitutability between products and to the cost asymmetries between countries.

Our results show that discriminatory tariffs have the effect of partially equalizing for cost differentials, so the low-cost country always faces the highest tariffs. The countries also use export taxes to secure part of their trading partners' tax bases. The chosen tariffs in the uniform regime are an average of the tariffs in the discriminatory regime. With simultaneous choice (game $S$ ) and tariffs chosen first (games $I$ ) the low-cost country always prefers the uniform regime and the high-cost the discriminatory regime. The preference of the country with intermediate cost level depends on whether it is closest to the low cost or the high cost. If the countries differ in cost then there is disagreement on the preferred regime. What is surprising about these results is that it is the low-cost country that prefers the uniform regime. The implication of this finding depends on how the cost structure of the model is interpreted. In many discussions of MFN it is seen as a benefit that developing countries wish to obtain from developed countries. If one interprets our model as one in which the developed country has a better technology, and so lower cost, then our results show that it is the developed that actually gains from the operation of MFN. In this case MFN may not imply the allocation of benefits that are often presumed. Alternatively, one could interpret the developing countries to have lower cost (perhaps through lower real wages). In this case, the gains of MFN do accrue to the developing countries so that they should pursue MFN status. In contrast, the developed countries would seek to maintain a discriminatory tariff regime.

The outcome with subsidies chosen before tariffs (game $E$ ) is different In this case all three countries prefer the uniform regime (unless there is considerable cost divergence between the two higher-cost countries). At first sight this might be taken as suggesting that there is a good chance MFN will be implemented if this timing structure is correct. However, after the tariff regime has been announced and the subsidies chosen there is an incentive for all countries to deviate and impose discriminatory tariffs. Hence, the MFN principle is not sustainable unless it is enforced by an outside body. This gives motivation for the existence of international agencies with the role of monitoring and enforcing tariff agreements.

\section{References}

Brander, J. A. (1995) "Strategic trade policy", in G. Grossman and K. Rogoff (eds.), Handbook of International Economics, Volume 3, 1395 - 1455, (Amsterdam: North-Holland).

Brander, J. and Spencer, B.J. (1984) "Tariff protection and imperfect competition", in H. Kierzkowski (ed.), Monopolistic Competition and International 
Trade (Oxford: Clarendon Press).

Brander J. A. and Spencer, B.J. (1985) "Export subsidies and international market share rivalry", Journal of International Economics, 18, 83-100.

Collie, D. R. and de Meza, D. (1986) "Inadequacies of the strategic rationale of export subsidies", Economics Letters, 22, 369-373.

Collie, D. R. and de Meza, D. (2003) "Comparative advantage and the pursuit of strategic trade policy", Economics Letters, 81, 279 - 283.

De Meza, D. (1986) "Export subsidies and high productivity: cause or effect", Canadian Journal of Economics, 19, 347 - 350.

Gatsios, K. (1990) "Preferential tariffs and the 'most favoured nation' principle: a note", Journal of International Economics, 28, 365 - 373.

Hoekman, B. M. and Kostecki, M.M. (2001) The Political Economy of the World Trading System (Oxford: Oxford University Press).

Horn, H., and Mavroidis, P.C. (2001) "Economic and legal aspects of the mostfavored nation clause", European Journal of Political Economy, 17, 233 279 .

Hwang H. and Mai, C.C. (1991) "Optimum discriminatory tariffs under oligopolistic competition", Canadian Journal of Economics, 24, 693 - 702.

Liao, P. and Wong, K. (2006) "Uniform versus discriminatory tariffs: when will export taxes be used?", Southern Economic Journal, 72, 915 - 925.

Neary, J.P. (1994) "Cost asymmetries in international subsidy games: should governments help winners or losers?" Journal of International Economics, 37, $197-218$.

Saggi, K. (2004) "Tariffs and the most favored nation clause." Journal of International Economics, 63, 341-368.

Saggi, K. (2006) "Preferential trade agreements and multilateral tariff cooperation", International Econoic Review, 47, pp. 29-57.

Saggi, K., and Yildiz, H.M. (2005) "An analysis of the MFN clause under asymmetries of cost and market structure," Canadian Journal of Economics, 38, pp. 242-254.

Saggi, K., and Yildiz, H.M. (2009) "Bilateralism, multilateralism, and the quest for global free trade," MPRA Paper 17558, University Library of Munich, Germany.

Tirole, J. (1988) The Theory of Industrial Organization (Cambridge: MIT Press). 
Yi, Sang-Seung (1996) "Endogenous formation of customs unions under imperfect competition: open regionalism is good," Journal of International Economics, 41, pp. 153-177. 